\title{
The Effect of Tb and Sm Ions on the Photochromic Behavior of Two Spiropyrans of Benzoxazine Series in Solution
}

\author{
Esam Bakeir, ${ }^{1}$ G. M. Attia, ${ }^{1}$ Maria Lukyanova, ${ }^{2}$ Boris Lukyanov, ${ }^{2}$ and M. S. A. Abdel-Mottaleb ${ }^{1}$ \\ ${ }^{1}$ Nanophotochemistry Lab, Department of Chemistry, Faculty of Science, Ain Shams University, Abbassia, Cairo 11566, Egypt \\ ${ }^{2}$ Department of Chemistry, Institute of Physical and Organic Chemistry, Southern Federal University, Rostov-on-Don 344006, Russia
}

Correspondence should be addressed to M. S. A. Abdel-Mottaleb, phochem08@photoenergy.org

Received 18 November 2007; Accepted 17 January 2008

Recommended by Bern Kohler

The photochromism of [ $7^{\prime}$-hydroxy-8'-formyl-3-methyl-4-oxospiro[1,3-benzoxazin-2,2' -[2H-1]benzopyran],SP(I), [7' -hydroxy$8^{\prime}$-formyl-3-benzyl-4-oxospiro[1,3-benzoxazin-2,2'-[2H-1] benzopyran] SP(II) and their coordination with $\mathrm{Tb}^{3+}$ and $\mathrm{Sm}^{3+}$ ions have been studied in DMF. UV/vis induced-color development due to heterolytic bond cleavage of SP(I) and SP(II) is greatly influenced by complexation with the lanthanide ions. The irradiation-induced color enhancement due to ring opening and thermal decoloration of the open forms of SP(I), SP(II) follows first-order kinetics. Physical characteristics of the studied systems such as colorability and relaxation time of thermal bleaching parameters were determined. Moreover, light-energy transfer-induced luminescence of lanthanide ions via coordination with the two spirobenzoxazines was monitored.

Copyright ( 2008 Esam Bakeir et al. This is an open access article distributed under the Creative Commons Attribution License, which permits unrestricted use, distribution, and reproduction in any medium, provided the original work is properly cited.

\section{INTRODUCTION}

Recently, many profitable applications of photochromic dyes, particularly spirooxazines, either as passive or active devices, have been proposed [1-13].

In some cases, it has been reported that thermal equilibrium between the closed (colorless form) and opened form (colored merocyanine quinonoid form) is affected by the change in solvent polarity $[14,15]$, since polar solvents promote the formation of the colored form at room temperature in the absence of light. The equilibrium between both forms is strongly displaced upon irradiation to the side of open-chain colored photomerocyanine and spontaneously converts to the colorless spiro form to reach thermal equilibrium immediately after removing the light [15]. The metalion coordination ability of photochromic spirocyclic compounds adequately substituted is of a great interest and is being the topic of several recent studies $[12,13]$. Search for molecules possessing better performances is valuable and it is important to continue to explore this subject. Here, we report on the possibility to stabilize the colored open forms of the recently synthesized spirobenzoxazines SP(I) and SP(II) toward thermal bleaching by coordination with $\mathrm{Tb}^{3+}$ and $\mathrm{Sm}^{3+}$ ions in polar DMF solvent. Moreover, the expected light-energy transfer-induced characteristic lumines- cence of lanthanide ions via complexation with the merocyanine quinonoid open forms of the two spirobenzoxazines will be explored.

\section{EXPERIMENTAL}

\subsection{Materials}

The metal chlorides (Sigma-Aldrich, 99.99\%) were used as received. The synthesis of [ $7^{\prime}$-hydroxy- $8^{\prime}$-formyl-3-methyl4-oxospiro [1,3-benzoxazin-2,2' - [2H-1]benzopyran],SP(I), [7' -hydroxy-8' -formyl-3-benzyl-4-oxospiro [1,3-benzoxazin-2,2' - [2H-1] benzopyran] SP(II) were described previously $[16,17]$. Spectroscopic pure grade solvents were used.

\subsection{Instruments}

UV-visible absorption spectra were recorded on a range (200-650 nm) using $\lambda$-Helios SP Pye-Unicam spectrophotometer and/or Ocean Optics US4000 fiber optics spectrophotometer. Continuous irradiation experiments were performed using a $150 \mathrm{~W}$ xenon arc lamp (PTI-LPS-220 Photon Technology International, USA) operated at $70 \mathrm{~W}$. Photochemical reactions were carried out in the spectrophotometric quartz cell with a homogeneously spread light on 
TABLE 1: The experimental values of absorption maxima of SP and its open form $\left(\lambda_{\mathrm{SP}}, \lambda_{\mathrm{open}}\right)$, SP ring opening rate constant $\left(k_{1}\right)$, thermal open form ring closure rate constant $\left(k_{-1}\right)$, equilibrium constant of the reversible reaction $\left(K_{e}\right)$, relaxation time of open form $\left(\tau_{\mathrm{open}-\mathrm{SP}}\right)$, and colorability in DMF at $295 \pm 1 \mathrm{~K}$. Error limits of the kinetics parameters are in the order of about $5 \%$.

\begin{tabular}{|c|c|c|c|c|c|c|c|}
\hline Compound & $\lambda_{\mathrm{SP}}(\mathrm{nm})$ & $\lambda_{\text {open }}(\mathrm{nm})$ & $k_{-1} \times 10^{3}\left(\mathrm{~min}^{-1}\right)$ & $k_{1} \times 10^{3}\left(\min ^{-1}\right)$ & $\tau_{\text {open-SP }}(\min )$ & $K_{e}$ & Colorability $\mathrm{M}^{-1} \mathrm{~cm}^{-1} \times 10^{-2}$ \\
\hline \multirow{2}{*}{$\mathrm{SP}(\mathrm{I})$} & 276 & \multirow{2}{*}{409} & \multirow{2}{*}{3.16} & \multirow{2}{*}{192} & \multirow{2}{*}{316} & \multirow{2}{*}{60} & \multirow{2}{*}{7.36} \\
\hline & 370 & & & & & & \\
\hline \multirow{2}{*}{ SP(II) } & 276 & \multirow{2}{*}{404} & \multirow{2}{*}{7.96} & \multirow{2}{*}{529} & \multirow{2}{*}{125} & \multirow{2}{*}{66} & \multirow{2}{*}{1.30} \\
\hline & 370 & & & & & & \\
\hline
\end{tabular}

the cell window to avoid stirring. Measurements were made on aerated solutions.

Fluorescence spectra were measured in the range (290$750 \mathrm{~nm}$ ) using Shimadzu RF5301 (PC) spectrofluorophotometer.

\subsection{Kinetics measurements}

The ring-closure reaction after photocoloration was monitored directly after removal of light at room temperature. First-order rate constants were obtained from the linear $\ln A$ versus time descending curves. By extrapolation of the obtained $\ln A / t$ plots to zero time, the absorbance $A_{o}$ of the open form or its complexes at $t=0$ was related to their "colorabilities" [18-21] using the expression $\left(A_{o} / c_{\mathrm{SP}} b\right)$, where $c_{\mathrm{SP}}$ is the initial concentration of SP and $b$ is the optical path length.

\section{RESULTS AND DISCUSSION}

\subsection{Absorption spectra}

The absorption spectrum of SP(I) and SP(II) displayed two bands at 276 and $370 \mathrm{~nm}$, Table 1, which are solvent independent (methanol, ethanol, and DMF solvents were tried). UV light-induced color development of both compounds was only remarkably observed in DMF solution.

Upon irradiation of $60 \mu \mathrm{M} \mathrm{SP}(\mathrm{I})$ solutions, the absorption spectra at $276 \mathrm{~nm}$ and $370 \mathrm{~nm}$ decreased and a new band at $409 \mathrm{~nm}$ appeared and its intensity increased by increasing the irradiation time. Addition of lanthanide chloride solution in DMF showed no change in the absorption band of $\mathrm{SP}(\mathrm{I})$ in the dark. However, irradiation of the $(1: 1$ molar ratio) solution of $\mathrm{SP}(\mathrm{I})$ in presence of $\mathrm{Tb}^{3+}$ and $\mathrm{Sm}^{3+}$, respectively, led to a new band at $412 \mathrm{~nm}$ and $414 \mathrm{~nm}$, Figure 1. Similar behavior observed for SP(II) in presence of lanthanide ions $\left(\mathrm{Tb}^{3+}, \mathrm{Sm}^{3+}\right)$ in DMF, Table 1. Thermal bleaching was monitored spectrophotometrically. First-order kinetics rate constants of the reversible close $\rightleftharpoons$ open reactions (see Scheme 2) were determined graphically (Figure 2, as an example) and data are collected in Tables 1 and 2.

Color development rate constant $\left(k_{1}\right)$ of the photomerocyanine form and the thermal bleaching rate constant $\left(k_{-1}\right)$ are used to estimate the equilibrium constant $\left(K_{e}=k_{1} / k_{-1}\right)$ of the forward photochemical ring opening reaction and the backward thermal bleaching one. The results of $K_{e}$ are summarized in Table 1 for the SP(I) and SP(II). Data for $\mathrm{Ln}^{3+}-\mathrm{SP}$ (I and II) appear in Table 2. The relaxation time of the open

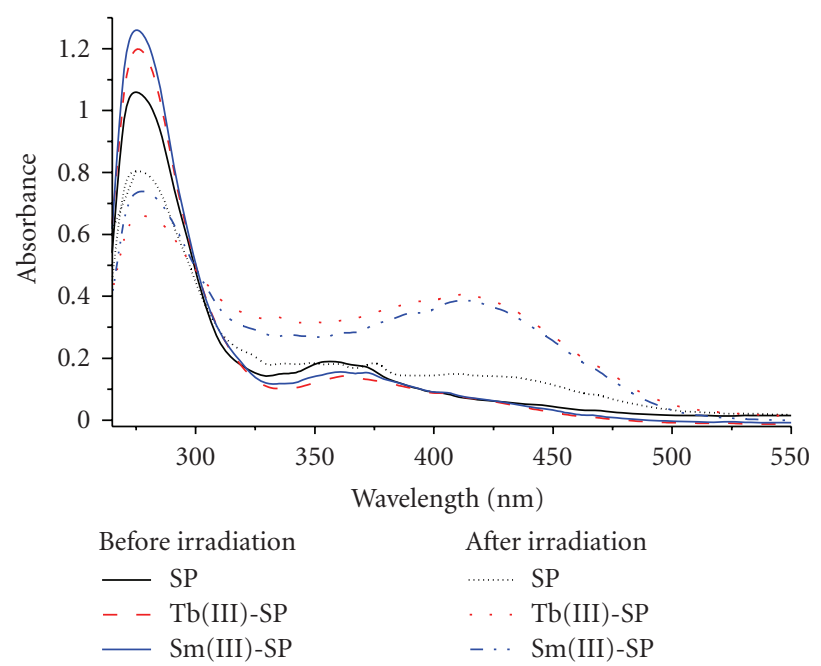

FIGURE 1: UV/vis absorption spectra of SP(I) and its complexes with $\mathrm{Tb}^{3+}$ and $\mathrm{Sm}^{3+}$ ions in DMF before and after light irradiation $\left([\mathrm{SP}(\mathrm{I})]=\left[\mathrm{Ln}^{3+}\right]=60 \mu \mathrm{M}\right)($ at $295 \pm 1 \mathrm{~K})$.

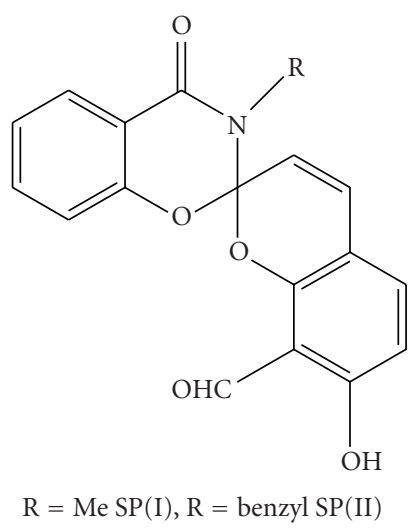

Scheme 1

form $\left(\tau_{\text {open-SO }}\right)$ given in Table 1 was obtained from the firstorder rate constant using the expression $\tau=1 / k_{-1}[18-21]$. The obtained relaxation time of SP and its complexes with lanthanide ions are relatively high [22], reflecting highly stabilized color form. The colored open MC form of the methylsubstituted SP(I) is more stable than that of the bulky benzyl derivative reflecting the influence of the constituent's nature and size. Moreover, the presence of the lanthanide ions 
<smiles>CCc1ccc(O)c(C=O)c1C=Cc1[o+]c2ccccc2c(=O)n1C</smiles>

Scheme 2: Illustration of the reversible structural transformation of SP to the MC form in response to light in the absence and presence of $\mathrm{Ln}^{3+}$ metal ion.

TABLE 2: The experimental values of absorption, $\mathrm{M}(\mathrm{III})$-SP formation rate constant $\left(k_{2}\right)$, thermal ring closure rate constant $\left(k_{-2}\right)$, equilib-

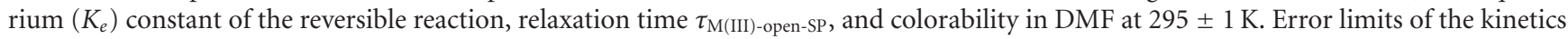
parameters are in the order of about $5 \%$.

\begin{tabular}{|c|c|c|c|c|c|c|}
\hline Complexes & $\lambda_{\text {open-M(III) }}(\mathrm{nm})$ & $k_{-2} \times 10^{3}\left(\mathrm{~min}^{-1}\right)$ & $k_{2} \times 10^{3}\left(\mathrm{~min}^{-1}\right)$ & $\tau_{\mathrm{M}(\mathrm{III}) \text {-open-SP }}(\min )$ & $K_{e}$ & Colorability $\mathrm{M}^{-1} \mathrm{~cm}^{-1} 10^{-2}$ \\
\hline $\mathrm{Tb}(\mathrm{III})-\mathrm{SP}(\mathrm{I})$ & 412 & 4.04 & 661 & 247 & 163 & 7.02 \\
\hline $\mathrm{Sm}(\mathrm{III})-\mathrm{SP}(\mathrm{I})$ & 414 & 4.55 & 258 & 219 & 56 & 7.85 \\
\hline $\mathrm{Tb}(\mathrm{III})-\mathrm{SP}(\mathrm{II})$ & 412 & 8.16 & 327 & 122 & 40 & 7.73 \\
\hline Sm(III)-SP(II) & 414 & 4.77 & 225 & 209 & 47 & 7.72 \\
\hline
\end{tabular}

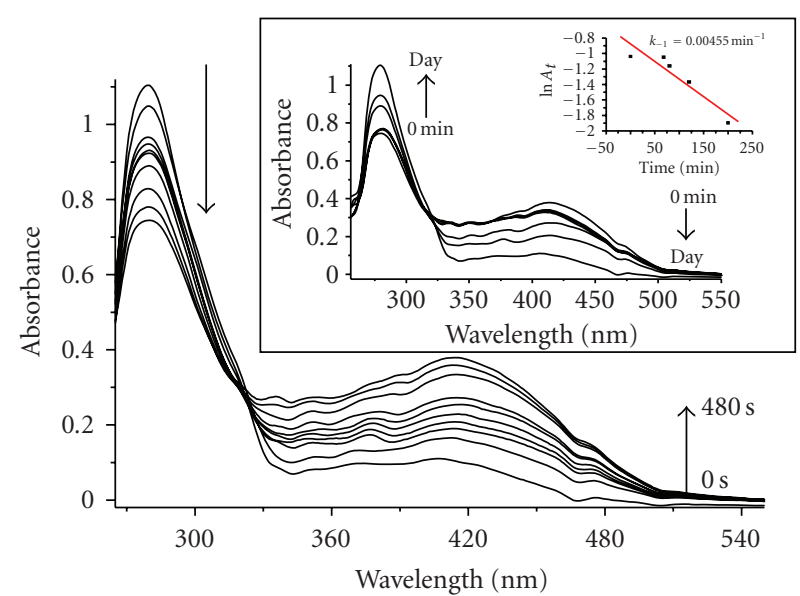

FIGURE 2: Effect of time of irradiation on the UV/vis absorption spectra of DMF solution of a mixture of $60 \mu \mathrm{M} \mathrm{Sm}{ }^{3+}$ and $60 \mu \mathrm{M}$ $\mathrm{SP}(\mathrm{II})$ (inset back ring closure reaction and the first-order plots of thermal decoloration of SP in dark) after UV irradiation at 295 $\pm 1 \mathrm{~K}$.

generally enhances the colorability of both SP derivatives reflecting the result of coordination with the MC forms.

Benzyl group substituent in SP(II) relative to the smaller methyl group substituent in $\mathrm{SP}(\mathrm{I})$ accelerates both rates of photocoloration and thermal bleaching as reflected in the higher values of the rate constants for SP(II) shown in Table 1. A significant decrease in relaxation time and colorability of the open form (MC quinonoid form) of the SP(II) was also induced due to the effect of more bulky benzyl group. Generally speaking, the presence of $\mathrm{Ln}^{3+}$ metal ions induced more bathochromic shift in the absorption band of

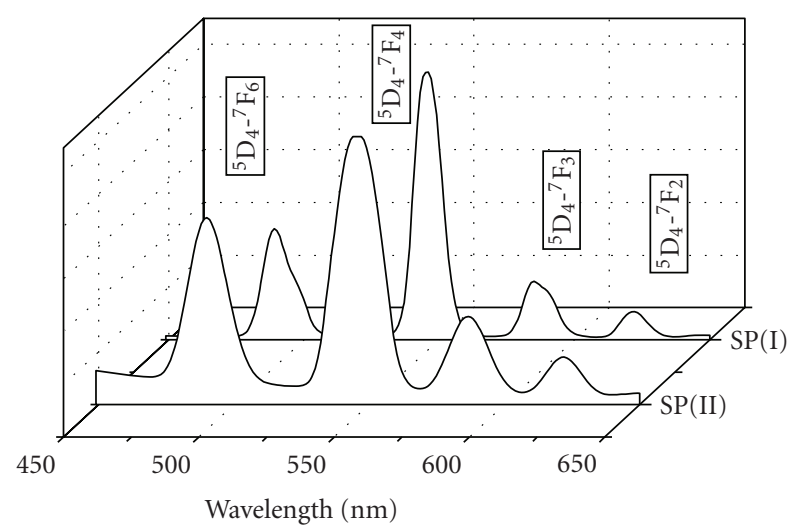

Figure 3: The sensitized luminescence spectra of $60 \mu \mathrm{M} \mathrm{Tb}^{3+}$ in the presence of $60 \mu \mathrm{M} \mathrm{SP}(\mathrm{I}, \mathrm{II})$ in DMF at room temperature.

the MC form, enhance colorability and relaxation time. Exception is the case of $\mathrm{Tb}^{3+}-\mathrm{SP}(\mathrm{I})$ complexes, where colorability and relaxation time slightly decrease.

\subsection{Luminescence spectra of Ianthanide complexes}

The ligand-centered luminescence was not observed in $\mathrm{Tb}^{3+}$ and $\mathrm{Sm}^{3+}$ complexes, whereas the typical characteristic narrow emission bands of the $\mathrm{Tb}^{3+}\left({ }^{5} \mathrm{D}_{4} \rightarrow{ }^{7} \mathrm{~F}_{6},{ }^{7} \mathrm{~F}_{5},{ }^{7} \mathrm{~F}_{4}\right.$, and $\left.{ }^{7} \mathrm{~F}_{3}\right)$ and $\mathrm{Sm}^{3+}\left({ }^{4} \mathrm{G}_{5 / 2} \rightarrow{ }^{6} \mathrm{H}_{5 / 2},{ }^{6} \mathrm{H}_{7 / 2},{ }^{6} \mathrm{H}_{9 / 2}\right.$, and $\left.{ }^{6} \mathrm{H}_{11 / 2}\right)\left(\right.$ at $\lambda_{\mathrm{ex}}=$ $360 \mathrm{~nm}$ ) ions can be detected in polar protic solvents upon excitation of the SP absorption band (see Figure 3). This indicates efficient energy transfer from the excited open MC form to the $\mathrm{Ln}^{3+}$ ions having lower energy levels [23]. 


\subsection{Conclusion}

The substituent nature and the presence of lanthanide metal ions in solution of recently synthesized photochromic spirobenzopyrans of benzoxazine series induced significant changes in its photochromic parameters. It could be generally concluded that the presence of lanthanide ions significantly enhances the rate constants of both color development of the light-induced formation of the open merocyaninelike quinonoid species and the rate constant of its thermal bleaching. In most cases, colorability is enhanced. Moreover, strong characteristic sensitized luminescence of the lanthanide ions was observed due to efficient population of its emissive states via energy transfer from the open forms of the spirobenzoxazines.

\section{ACKNOWLEDGEMENT}

Russian Foundation for Basic Research supported the Russian team (Grant 07-03-00234).

\section{REFERENCES}

[1] F. Ebisawa, M. Hoshino, and K. Sukegawa, "Self-holding photochromic polymer Mach-Zehnder optical switch," Applied Physics Letters, vol. 65, no. 23, pp. 2919-2921, 1994.

[2] M. Seibold, H. Port, and H. C. Wolf, "Fulgides as light switches for intra-supermolecular energy transfer," Molecular Crystals and Liquid Crystals, vol. 283, no. 1, pp. 75-80, 1996.

[3] M. Hamano and M. Irie, "Rewritable near-field optical recording on photochromic thin films," Japanese Journal of Applied Physics, vol. 35, no. 3, pp. 1764-1767, 1996.

[4] M. Irie and M. Mohri, "Thermally irreversible photochromic systems. Reversible photocyclization of diarylethene derivatives," Journal of Organic Chemistry, vol. 53, no. 4, pp. 803-808, 1988.

[5] R. Wortmann, P. M. Lundquist, R. J. Twieg, et al., "A novel sensitized photochromic organic glass for holographic optical storage," Applied Physics Letters, vol. 69, no. 12, pp. 1657-1659, 1996.

[6] R. M. Tarkka, M. E. Talbot, D. J. Brady, and G. B. Schuster, "Holographic storage in a near-ir sensitive photochromic dye," Optics Communications, vol. 109, no. 1-2, pp. 54-58, 1994.

[7] J. P. Hagen, I. Becerra, D. Drakulich, and R. O. Dillon, "Effect of antenna porphyrins and phthalocyanines on the photochromism of benzospiropyrans in poly(methyl methacrylate) films," Thin Solid Films, vol. 398-399, no. 1, pp. 104-109, 2001.

[8] R. C. Bertelson, "Photochromic processes involving heterolytic cleavage," in Photochromism, G. H. Brown, Ed., vol. 3 of Techniques of Chemistry, pp. 45-431, John Wiley \& Sons, New York, NY, USA, 1971.

[9] R. Guglielmetti, "Spiropyrans have been extensively studied," in Photochromism: Molecules and Systems, H. Dürr and H. Bouas-Laurent, Eds., vol. 40 of Studies in Organic Chemistry, pp. 314-466, Elsevier, Amsterdam, The Netherlands, 1990.

[10] J. B. Flannery Jr., "Photo- and thermochromic transients from substituted 1',3',3'-trimethylindolinobenzospiropyrans," Journal of the American Chemical Society, vol. 90, no. 21, pp. 5660-5671, 1968.

[11] T. Bercovici, R. Heiligman-Rim, and E. Fischer, "Photochromism in spiropyrans. Part VI trimethylindolino-ben- zospiropyran and its derivatives," Molecular Photochemistry, vol. 1, pp. 23-55, 1969.

[12] V. I. Minkin, "Photo-, thermo-, solvato-, and electrochromic spiroheterocyclic compounds," Chemical Reviews, vol. 104, no. 5, pp. 2751-2776, 2004.

[13] A. V. Chernyshev, N. A. Voloshin, I. M. Raskita, A. V. Metelitsa, and V. I. Minkin, "Photo- and ionochromism of 5' -(4,5-diphenyl-1,3-oxazol-2-yl) substituted spiro[indoline-naphthopyrans]," Journal of Photochemistry and Photobiology A, vol. 184, no. 3, pp. 289-297, 2006.

[14] T. Deligeorgiev, S. Minkovska, B. Jeliazkova, and S. Rakovsky, "Synthesis of photochromic chelating spironaphthoxazines," Dyes and Pigments, vol. 53, no. 2, pp. 101-108, 2002.

[15] S. Minkovska, B. Jeliazkova, E. Borisova, L. Avramov, and T. Deligeorgiev, "Substituent and solvent effect on the photochromic properties of a series of spiroindolinonaphthooxazines," Journal of Photochemistry and Photobiology A, vol. 163, no. 1-2, pp. 121-126, 2004.

[16] Yu. S. Alekseenko, B. Lukyanov, A. N. Utenyshev, et al., "Photo-and thermochromic spiranes. 24. Novel photochromic spiropyrans from 2,4-dihydroxyisophthalaldehyde," Chemistry of Heterocyclic Compounds, vol. 42, no. 6, pp. 803-812, 2006.

[17] B. Lukyanov and M. B. Lukyanova, "Spiropyrans: synthesis, properties, and application," Chemistry of Heterocyclic Compounds, vol. 41, no. 3, pp. 281-311, 2005.

[18] G. Favaro, V. Malatesta, U. Mazzucato, G. Ottavi, and A. Romani, "Thermally reversible photoconversion of spiroindoline-naphtho-oxazines to photomerocyanines: a photochemical and kinetic study," Journal of Photochemistry and Photobiology A, vol. 87, no. 3, pp. 235-241, 1995.

[19] S. Kawauchi, H. Yoshida, N. Yamashina, M. Ohira, S. Saeda, and M. Irie, "A new photochromic spiro[3H-1,4-oxazine]," Bulletin of the Chemical Society of Japan, vol. 63, no. 1, pp. 267268, 1990.

[20] J.-L. Pozzo, A. Samat, R. Guglielmetti, and D. de Keukeleire, "Solvatochromic and photochromic characteristics of new 1,3-dihydrospiro[ $[2 H$-indole-2,2' - $[2 H]$-bipyrido $[3,2-f][2,3-$ h][1,4] benzoxazines]," Journal of the Chemical Society, Perkin Transactions 2, no. 7, pp. 1327-1332, 1993.

[21] V. Pimienta, C. Frouté, M. H. Deniel, D. Lavabre, R. Guglielmetti, and J. C. Micheau, "Kinetic modelling of the photochromism and photodegradation of a spiro[indoline-naphthoxazine]," Journal of Photochemistry and Photobiology A, vol. 122, no. 3, pp. 199-204, 1999.

[22] B. B. Safoklov, B. Lukyanov, A. O. Bulanov, et al., "Photoand thermochromic spiropyrans. 21. 2, 8" -Formyl-3,6"dimethyl-4-oxospiro(3,4-dihydro-2H-1,3-benzoxazine-2,2" $[2 \mathrm{H}]$ chromene) possessing photochromic properties in the solid phase," Russian Chemical Bulletin, vol. 51, no. 3, pp. 462-466, 2002.

[23] K. A. Chibisov and H. Görner, "Complexes of spiropyranderived merocyanines with metal ions: relaxation kinetics, photochemistry and solvent effects," Chemical Physics, vol. 237, no. 3, pp. 425-442, 1998. 


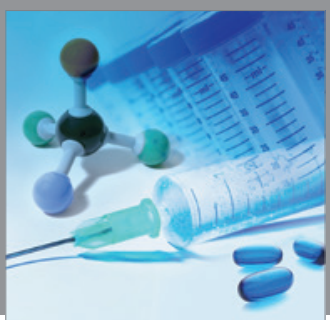

International Journal of

Medicinal Chemistry

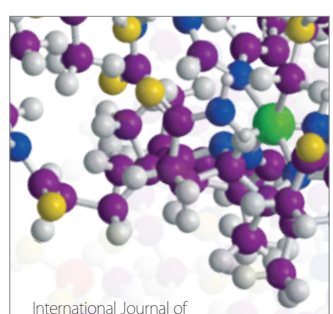

Carbohydrate Chemistry

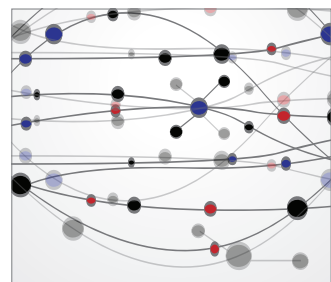

The Scientific World Journal
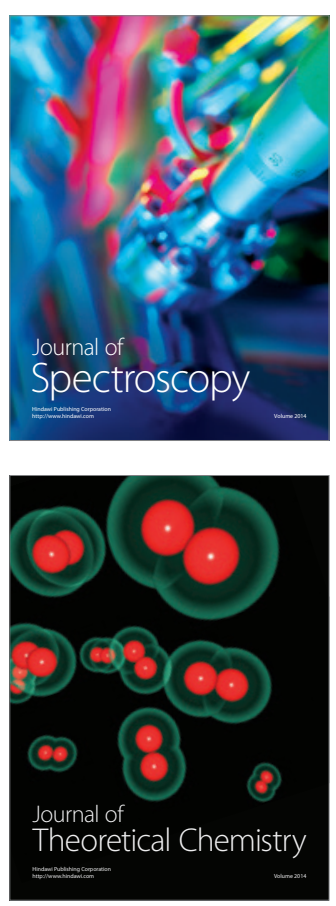
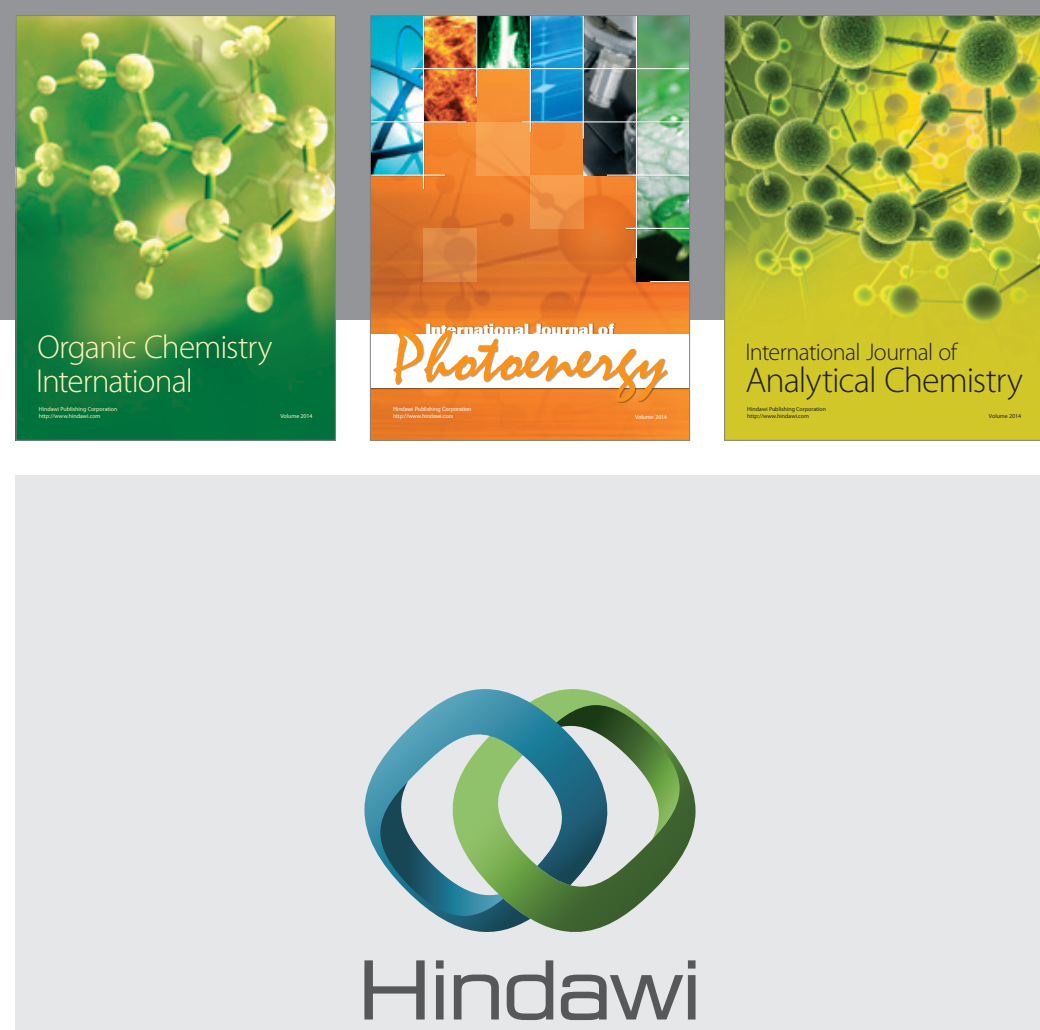

Submit your manuscripts at

http://www.hindawi.com
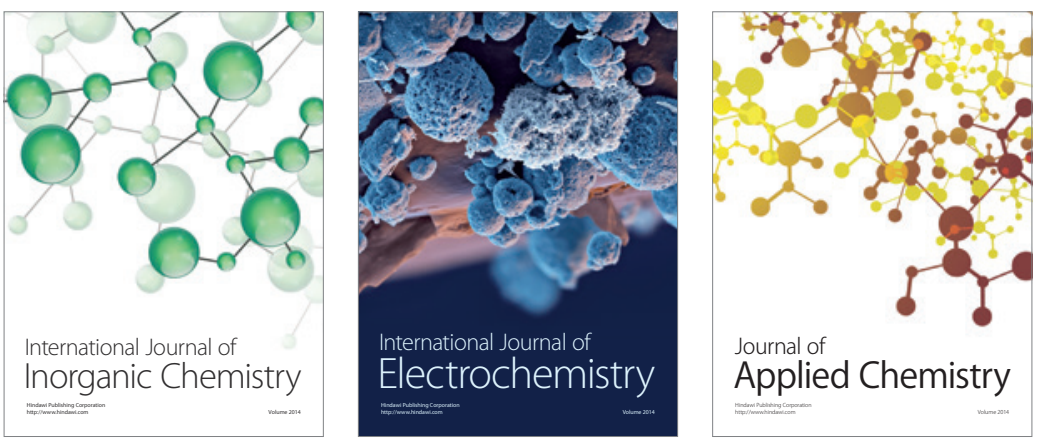

Journal of

Applied Chemistry
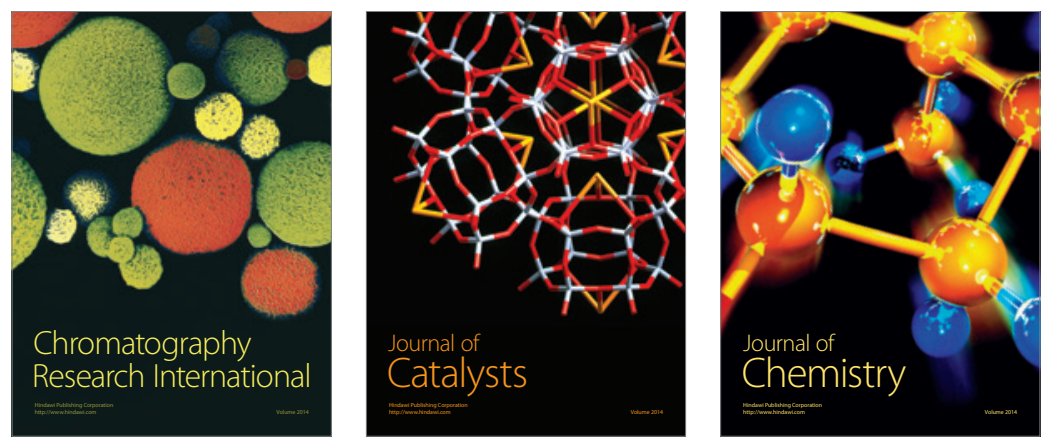
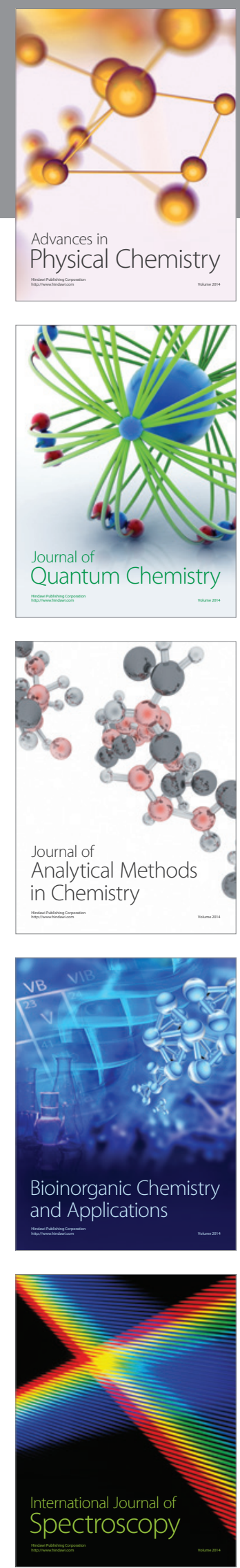